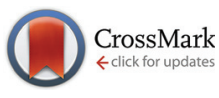

Cite this: Food Funct., 2015, 6, 2240

\title{
Melissa officinalis L. decoctions as functional beverages: a bioactive approach and chemical characterization
}

\author{
Márcio Carocho, ${ }^{a, b}$ Lillian Barros, ${ }^{a}$ Ricardo C. Calhelha, ${ }^{a, c}$ Ana Ćirić, ${ }^{d}$ \\ Marina Soković, ${ }^{d}$ Celestino Santos-Buelga, ${ }^{e}$ Patricia Morales ${ }^{b}$ and \\ Isabel C. F. R. Ferreira*a
}

\begin{abstract}
Lemon balm (Melissa officinalis L.) is a member of the Lamiaceae family with a long story of human consumption. It has been consumed for decades, directly in food and as a decoction or an infusion for its medicinal purposes. In this manuscript, a detailed chemical characterization of the decoction of this plant is described, encompassing antimicrobial, antioxidant and antitumor activities. Rosmarinic acid and lithospermic acid A were the most abundant phenolic compounds. Quinic acid, fructose, glucose and $\gamma$-tocopherol were the most abundant within their groups of molecules. M. officinalis decoctions were active against a wide range of microorganisms, Pseudomonas aeruginosa and Salmonella typhimurium, and Penicillium funiculosum being the most sensitive bacteria and fungi, respectively. The growth inhibition of different human tumor cell lines (mainly MCF-7 and HepG2) was also observed, as also high free radical scavenging activity and reducing power. This manuscript highlights some beneficial effects of these functional beverages.
\end{abstract}

Received 24th March 2015 Accepted 30th May 2015

DOI: $10.1039 /$ c5fo00309a www.rsc.org/foodfunction ries for its outstanding traditional, medicinal effects on health and against illnesses. It is credited for its antibacterial, antifungal, and anti-inflammatory effects. Furthermore, it acts as an expectorant, relieves digestion, headaches and rheumatism. $^{2,3}$ Recently, apart from some empirical claims of its applicability, other effects have been discovered for this plant, namely against neurodegenerative diseases, and antitumor, antiproliferative, anticholinesterase, antioxidant and anti-Alzheimer effects. ${ }^{2,4}$ Further uses have also been explored, namely as a food ingredient for stabilization and preservation. ${ }^{5}$ The beneficial effects found in the extracts of $M$. officinalis could in part be attributed to its phenolic compounds, namely the caffeic acid dimer rosmarinic acid, and other caffeic acid derivatives. ${ }^{3}$

The most consumed drinks in the world are "teas". They are consumed as functional beverages, thanks to the beneficial properties of the plants used in them. The two most important methods of preparation of "teas" are infusions and decoctions, with the latter being the most common and more effective for a better extraction of larger molecules like tannins and other hard extracting ones. ${ }^{6}$ Some studies, comparing infusions and decoctions have proven that the decoctions have better extracting capacity and this can be translated in higher levels of phenolic compounds and, therefore, increased bioactivity. ${ }^{7,8}$

Given the outstanding effects of lemon balm on human health and its potential as a functional beverage, in the 
present work, its decoctions have been chemically characterized (phenolic compounds, organic acids, sugars and tocopherols) and evaluated with respect to its antimicrobial, antioxidant and antitumor in vitro effects.

\section{Materials and methods}

\subsection{Sample and decoction preparation}

Melissa officinalis L. dry leaves were provided by the company Pragmático Aroma Lda. ("Mais Ervas") based in Trás-osMontes, Portugal. After confirmation of the taxonomical identification, the samples were subjected to a decoction extraction, in which $1 \mathrm{~g}$ of the plants was added to $200 \mathrm{~mL}$ of cold distilled water. After heating, it was left to boil for $5 \mathrm{~min}$ and stand at room temperature for 5 more minutes. After filtration through a Whatman no. 4 filter paper, the obtained decoctions were frozen and lyophilized and all the assays were performed using these samples. The extractions and all the assays were carried out in triplicate and the results were expressed as mean values \pm standard deviations (SD).

\subsection{Standards and reagents}

Acetonitrile, $n$-hexane, ethyl acetate (HPLC grade) and sulphuric acid were acquired from Fisher Scientific (Lisbon, Portugal). Formic acid was purchased from Panreac (Barcelona, Spain). Sugar standards (D(-)-fructose, $\mathrm{D}(+)$-glucose anhydrous and $\mathrm{D}(+)$-sucrose), organic acid standards (malic, shikimic, oxalic and quinic acids), tocopherol standards $(\alpha, \beta, \gamma$, and $\delta$ isoforms), trolox (6-hydroxy-2,5,7,8-tetramethylchroman-2-carboxylic acid), acetic acid, ellipticine, sulforhodamine B (SRB), trypan blue, trichloroacetic acid (TCA), phosphate buffered saline (PBS), and Tris buffer were acquired from Sigma Chemical Co. (Saint Louis, MO, USA). Dimethyl sulfoxide (DMSO) was obtained from Merck (KGaA, Germany). Phenolic compound standards (caffeic and rosmarinic acid) were purchased from Extrasynthese (Genay, France). 2,2-Diphenyl-1-picrylhydrazyl (DPPH) was obtained from Alfa Aesar (Ward Hill, MA, USA). Fetal bovine serum (FBS), L-glutamine, Hank's balanced salt solution (HBSS), trypsin-EDTA (ethylenediaminetetraacetic acid), nonessential amino acid solution $(2 \mathrm{mM})$, penicillin/ streptomycin solution $\left(100 \mathrm{U} \mathrm{mL}^{-1}\right.$ and $100 \mathrm{mg} \mathrm{mL}^{-1}$, respectively), RPMI-1640, and DMEM media were acquired from HyClone (Logan, UT, USA). Mueller-Hinton agar (MH) and malt agar (MA) were obtained from the Institute of Immunology and Virology, Torlak (Belgrade, Serbia). Racemic tocol $\left(50 \mathrm{mg} \mathrm{mL}{ }^{-1}\right.$ ) was purchased from Matreya (Pleasant Gap, PA, USA). All other chemicals were obtained from official scientific retailers. Water was treated by means of a Milli-Q water purification system (TGI Pure Water Systems, Greenville, SC, USA).

\subsection{Chemical characterization}

2.3.1 Phenolic compounds. Phenolic compounds were determined by HPLC (Hewlett-Packard 1100, Agilent Technologies, Santa Clara, CA, USA) as previously described by Barros et al. ${ }^{9}$ Double online detection was carried out in a DAD using $280 \mathrm{~nm}$ as the preferred wavelength and using a mass spectrometer connected to the HPLC system via the DAD cell outlet. Mass spectrometric detection was performed by means of an API 3200 (Applied Biosystems, Darmstadt, Germany) triple quadrupole-ion trap analyser equipped with an ESI source. Spectra were recorded in negative ion mode between $\mathrm{m} / \mathrm{z} 100$ and 1700 . The phenolic compounds were identified by comparing their retention time, UV-vis and mass spectra with those obtained from standard solutions, when available. Otherwise, the compounds were tentatively identified by comparing the obtained information with available data in our compound library or with that reported in the literature. For quantitative analysis, a 5-level calibration curve was obtained by plotting the areas of the peaks recorded at $280 \mathrm{~nm}$ against known concentrations $\left(1-100 \mathrm{mg} \mathrm{mL}^{-1}\right)$ of phenolic standards, i.e., caffeic acid $\left(y=359 x+488.4 ; R^{2}=0.999\right)$ and rosmarinic acid $\left(y=312.2 x-424.06 ; R^{2}=0.999\right)$. Compound quantification was performed through the calibration curve of the phenolic standard of the same group. The results were expressed in $\mathrm{mg}$ per $\mathrm{g}$ of lyophilized decoctions.

2.3.2. Organic acids. Organic acids were determined following a procedure previously described by Pinela et al. ${ }^{10}$ Analyses were performed on a Shimadzu 20A series ultra-fast liquid chromatograph (UFLC, Shimadzu Cooperation, Kyoto, Japan) coupled to a diode array detector (DAD, Shimadzu), using $215 \mathrm{~nm}$ and $245 \mathrm{~nm}$ (for ascorbic acid) as the preferred wavelengths. Separation was achieved on a Sphereclone (Phenomenex, Torrance, CA, USA) reverse phase C18 column $\left(5 \mu \mathrm{m}, 250 \mathrm{~mm} \times 4.6 \mathrm{~mm}\right.$ i.d) thermostated at $35{ }^{\circ} \mathrm{C}$. Analytes were eluted with $3.6 \mathrm{mM}$ sulphuric acid at a flow-rate of $0.8 \mathrm{~mL} \mathrm{~min}{ }^{-1}$. The organic acids found were quantified by comparison of peak areas recorded at $215 \mathrm{~nm}$ with calibration curves obtained from commercial standards of each compound: oxalic acid $\left(y=9 \times 10^{6} x+377946 ; R^{2}=0.994\right)$; quinic acid $\left(y=612327 x+16563 ; R^{2}=1\right)$; malic acid $(y=863548 x+$ $\left.55591 ; R^{2}=0.999\right)$; shikimic acid $\left(y=8 \times 10^{7} x+55079 ; R^{2}=\right.$ $0.999)$; citric acid $\left(y=1 \times 10^{6} x+16276 ; R^{2}=1\right)$; succinic acid $\left(y=603298 x+4994.1 ; R^{2}=1\right)$; fumaric acid $(y=148083 x+$ $\left.96092 ; R^{2}=1\right)$. The results were expressed in $\mathrm{mg}$ per $\mathrm{g}$ of lyophilized decoctions.

2.3.3. Free sugars. Free sugars were determined by HPLC coupled to a refractive index (RI) detector as described by Pinela et al. ${ }^{10}$ The equipment consisted of a pump (Knauer, Smartline System 1000, Berlin, Germany), a degasser (Smart line Manager 5000), an autosampler (AS-2057 Jasco, Easton, MD, USA), and a RI detector (Knauer Smartline 2300). The chromatographic separation was achieved with an Eurospher 100-5 $\mathrm{NH}_{2}$ column $(5 \mu \mathrm{m}, 250 \mathrm{~mm} \times 4.6 \mathrm{~mm}$ i.d., Knauer $)$ operating at $35{ }^{\circ} \mathrm{C}(7971 \mathrm{R}$ Grace oven). The mobile phase was acetonitrile/deionized water, $70: 30(\mathrm{v} / \mathrm{v})$ at a flow rate of $1 \mathrm{~mL}$ $\mathrm{min}^{-1}$. The identification was achieved by comparing the relative retention times of the sample peaks with standards. Quantification was made by the internal standard method, and the results are expressed in $\mathrm{mg}$ per $\mathrm{g}$ of lyophilized decoctions. 
2.3.4. Tocopherols. Tocopherols were determined by following a procedure previously described by Guimarães et $a .^{11}$ The HPLC system as described above for sugar analysis, was connected to a fluorescence detector (FP-2020; Jasco, Easton, MD, USA) programmed for excitation at $290 \mathrm{~nm}$ and emission at $330 \mathrm{~nm}$. The chromatographic separation was achieved with a polyamide II normal-phase column $(5 \mu \mathrm{m}, 250 \mathrm{~mm} \times 4.6 \mathrm{~mm}$ i.d., YMC Waters), operating at $35^{\circ} \mathrm{C}$. The mobile phase used was a mixture of $n$-hexane and ethyl acetate $(70: 30, \mathrm{v} / \mathrm{v})$ at a flow rate of $1 \mathrm{~mL} \mathrm{~min}^{-1}$. The compounds were identified by chromatographic comparisons to authentic standards. Quantification was based on the fluorescence signal response, using the internal standard method. The tocopherol contents in the samples were expressed in $\mu \mathrm{g}$ per $\mathrm{g}$ of lyophilized decoctions.

\subsection{Evaluation of bioactive properties}

2.4.1. General. Lyophilized decoctions were redissolved in water $\left(5 \mathrm{mg} \mathrm{mL}^{-1}\right.$ for antimicrobial and antioxidant activity evaluation, or $8 \mathrm{mg} \mathrm{mL} \mathrm{m}^{-1}$ for antitumor activity and hepatotoxicity evaluation). The final solutions were further diluted to different concentrations to be subjected to the distinct in vitro assays.

2.4.2. Antibacterial activity. The methodology previously described by Petrović et al. ${ }^{12}$ and Vieira et al. ${ }^{13}$ was followed. The following Gram-negative bacteria were used: Escherichia coli (ATCC (American type culture collection) 35210), Pseudomonas aeruginosa (ATCC 27853), Salmonella typhimurium (ATCC 13311), Enterobacter cloacae (ATCC 35030), and Grampositive bacteria: Staphylococcus aureus (ATCC 6538), Bacillus cereus (clinical isolate), Micrococcus flavus (ATCC 10240), and Listeria monocytogenes (NCTC (National collection of type cultures) 7973). These microorganisms were obtained from the Mycological Laboratory, Department of Plant Physiology, Institute for Biological Research "Siniša Stanković" at the University of Belgrade in Serbia. A fresh overnight culture of bacteria was adjusted with a spectrophotometer to a concentration of $1 \times$ $10^{5} \mathrm{CFU} \mathrm{mL}^{-1}$. The requested colony forming units (CFU) $\mathrm{mL}^{-1}$ corresponded to a bacterial suspension determined using a spectrophotometer at $625 \mathrm{~nm}$. Dilutions of the inocula were cultured on solid medium to verify the absence of contamination and to check the validity of the inoculum. The sample solutions were pipetted into the wells containing $100 \mu \mathrm{L}$ of Tryptic Soy Broth (TSB), with $10 \mu \mathrm{L}$ of the inoculum being added to all the wells. The microplates were incubated for $24 \mathrm{~h}$ at $37^{\circ} \mathrm{C}$. The MIC (minimal inhibitory concentration) of the samples was determined by adding $40 \mu \mathrm{L}$ of iodonitrotetrazolium chloride (INT) $\left(0.2 \mathrm{mg} \mathrm{mL}^{-1}\right)$ and by incubation at $37{ }^{\circ} \mathrm{C}$ for $30 \mathrm{~min}$. The lowest concentration that produced a significant inhibition (around 50\%) of the growth of the bacteria in comparison with the positive control was identified as the MIC. The MICs obtained from the susceptibility testing of various bacteria to the tested samples were also determined by a colorimetric microbial viability assay based on the reduction of INT color and compared with the positive control for each bacterial strain. MBC (minimal bactericidal concentration) was determined by serial sub-cultivation of $10 \mu \mathrm{L}$ into microplates containing $100 \mu \mathrm{L}$ of TSB. The lowest concentration that showed no growth after this sub-culturing was regarded as the MBC. Streptomycin and ampicillin were used as positive controls, while $5 \%$ dimethyl sulfoxide (DMSO) was used as a negative control. The results of MIC and MBC were expressed in $\mathrm{mg}$ per $\mathrm{mL}$ of the aqueous solutions of the lyophilized decoctions.

2.4.3. Antifungal activity. The methodology previously described by Petrović et al. ${ }^{12}$ and Vieira et al. ${ }^{13}$ was followed. The following microfungi were used: Aspergillus fumigatus (ATCC 1022), Aspergillus ochraceus (ATCC 12066), Aspergillus versicolor (ATCC 11730), Aspergillus niger (ATCC 6275), Trichoderma viride (IAM (Culture Collection, Centre for Cellular and Molecular Research, Institute of Molecular and Cellular Biosciences, The University of Tokyo, Japan) 5061), Penicillium funiculosum (ATCC 36839), Penicillium ochrochloron (ATCC 9112) and Penicillium verrucosum var. cyclopium (food isolate). These organisms were also obtained from the Mycological Laboratory, Department of Plant Physiology, Institute for Biological Research "Siniša Stanković" at the University of Belgrade in Serbia. The micromycetes were maintained on malt agar (MA) and the cultures were stored at $4^{\circ} \mathrm{C}$ and sub-cultured once a month. The fungal spores were washed from the surface of agar plates with sterile $0.85 \%$ saline containing $0.1 \%$ Tween $80(\mathrm{v} / \mathrm{v})$. The spore suspension was adjusted with sterile saline to a concentration of approximately $1.0 \times 10^{5}$ in a final volume of $100 \mu \mathrm{L}$ per well. The inocula were stored at $4{ }^{\circ} \mathrm{C}$ for further use. Dilutions of the inocula were cultured on solid MA to verify the absence of contamination and to check the validity of the inoculum. The MIC determination was performed by a serial dilution technique using 96-well microplates. The sample solutions were added to the broth malt medium with the fungal inoculum. The microplates were incubated for $72 \mathrm{~h}$ at $28{ }^{\circ} \mathrm{C}^{14}$ The lowest concentrations without visible growth (using a binocular microscope) were defined as the MIC. The minimum fungicidal concentrations (MFCs) were determined by serial sub-cultivation of $2 \mu \mathrm{L}$ in microtiter plates containing $100 \mu \mathrm{L}$ of malt broth per well and further by incubation for $72 \mathrm{~h}$ at $28{ }^{\circ} \mathrm{C}$. The lowest concentration with no visible growth was defined as the MFC, indicating 99.5\% killing of the original inoculum. 5\% DMSO was used as a negative control, while bifonazole and ketoconazole were used as positive controls. The results of MIC and MFC were expressed as mg per $\mathrm{mL}$ of the aqueous solutions of the lyophilized decoctions.

2.4.4. Antioxidant activity. The DPPH radical-scavenging activity was evaluated using an ELX800 microplate reader (BioTek Instruments, Inc.; Winooski, VT, USA) and calculated as a percentage of DPPH discolouration after 1 hour of incubation with the antioxidant extract, using the formula: $\left[\left(A_{\mathrm{DPPH}}-A_{\mathrm{S}}\right) /\right.$ $\left.A_{\mathrm{DPPH}}\right] \times 100$, where $A_{\mathrm{S}}$ is the absorbance of the solution containing the sample at $515 \mathrm{~nm}$, and $A_{\mathrm{DPPH}}$ is the absorbance of the DPPH solution. Reducing power was evaluated by the capacity to reduce $\mathrm{Fe}^{3+}$ into $\mathrm{Fe}^{2+}$, measuring the absorbance at $690 \mathrm{~nm}$ in the microplate reader mentioned above. Inhibition of $\beta$-carotene bleaching was evaluated through the $\beta$-carotene/ linoleate assay; the neutralization of linoleate free radicals avoids $\beta$-carotene bleaching, which is measured by the 
formula: ( $\beta$-carotene absorbance after $2 \mathrm{~h}$ of assay/initial absorbance) $\times 100$. Lipid peroxidation inhibition in porcine (Sus scrofa) brain homogenates was evaluated by the decrease in thiobarbituric acid reactive substances (TBARS); the colour intensity of the malondialdehyde-thiobarbituric acid (MDA-TBA) was measured by its absorbance at $532 \mathrm{~nm}$; the inhibition ratio (\%) was calculated using the following formula: $[(A-B) / A] \times 100 \%$, where $A$ and $B$ were the absorbances of the control and the sample solution, respectively. ${ }^{9}$ Trolox was used as a positive control. The results were expressed as $\mathrm{EC}_{50}$ values (sample concentration providing $50 \%$ of the antioxidant activity or 0.5 of absorbance in the reducing power assay) in $\mu \mathrm{g}$ per $\mathrm{mL}$ of the aqueous solutions of the lyophilized decoctions.

2.4.5. Antitumor activity and hepatotoxicity. Four human tumor cell lines were tested: MCF7 (breast adenocarcinoma), NCI-H460 (non-small cell lung carcinoma), HeLa (cervical carcinoma) and HepG2 (hepatocellular carcinoma). Cells were routinely maintained as adherent cell cultures in RPMI1640 medium containing $10 \%$ heat-inactivated FBS and $2 \mathrm{mM}$ glutamine at $37{ }^{\circ} \mathrm{C}$, in a humidified air incubator containing $5 \% \mathrm{CO}_{2}$. Each cell line was plated at an appropriate density $\left(7.5 \times 10^{3}\right.$ cells per well for MCF7 and NCI-H460 or $1.0 \times 10^{4}$ cells per well for HeLa and HepG2) in 96-well plates.

For hepatotoxicity evaluation, a cell culture was prepared from a fresh porcine liver obtained from a local slaughter house, and it was designed as PLP2. Briefly, the liver tissues were rinsed in Hank's balanced salt solution containing $100 \mathrm{U}$ $\mathrm{mL}^{-1}$ penicillin, $100 \mu \mathrm{g} \mathrm{mL}^{-1}$ streptomycin and were divided into $1 \times 1 \mathrm{~mm}^{3}$ explants. Some of these explants were placed in $25 \mathrm{~cm}^{2}$ tissue flasks in DMEM medium supplemented with $10 \%$ fetal bovine serum, $2 \mathrm{mM}$ nonessential amino acids and $100 \mathrm{U} \mathrm{mL}^{-1}$ penicillin, $100 \mathrm{mg} \mathrm{mL}^{-1}$ streptomycin and incubated at $37{ }^{\circ} \mathrm{C}$ under a humidified atmosphere containing 5\% $\mathrm{CO}_{2}$. The medium was changed every two days. Cultivation of the cells was continued with direct monitoring every two to three days using a phase contrast microscope. Before the confluence was reached, the cells were subcultured and plated in 96-well plates at a density of $1.0 \times 10^{4}$ cells per well, and cultivated in DMEM medium with $10 \% \mathrm{FBS}, 100 \mathrm{U} \mathrm{mL}^{-1}$ penicillin and $100 \mu \mathrm{g} \mathrm{mL}{ }^{-1}$ streptomycin. ${ }^{15}$

The sulphorhodamine B assay was performed according to a procedure previously described by Guimarães et al. ${ }^{11}$ Ellipticine was used as a positive control. The results were expressed as $\mathrm{GI}_{50}$ values (sample concentration that inhibited $50 \%$ of the net cell growth) in $\mu \mathrm{g}$ per $\mathrm{mL}$ of the aqueous solutions of the lyophilized decoctions.

\section{Results and discussion}

\subsection{Chemical characterization}

Fig. 1 shows a chromatogram with the phenolic profile of M. officinalis decoctions recorded at $280 \mathrm{~nm}$. Twenty compounds could be detected and identified, mostly corresponding to caffeic acid derivatives. Peak characteristics and tentative identifications based on their UV and mass spectra by comparing with the available literature ${ }^{16-22}$ are presented in Table 1. Although there are studies about the phenolic profile in aqueous or alcoholic extracts of $M$. officinalis, ${ }^{3,23-30}$ as far as we know, this is the first report regarding phenolic characterization in decoctions of this plant. In a previous study, ${ }^{3}$ the phenolic characterization of infusions obtained from different samples of $M$. officinalis (cultivated, in vitro cultured, commercial granulate and bag) had been already performed, being the profiles similar to the one observed in the decoctions studied herein.

Compound 1 was identified as 3-(3,4-dihydroxyphenyl)lactic acid, based on its fragmentation pattern, ${ }^{17}$ and previous identification in $M$. officinalis infusions. ${ }^{3}$ Compounds $5\left([\mathbf{M}-\mathbf{H}]^{-}\right.$at $\left.m / z 179\right)$ and $\mathbf{1 5}\left([\mathrm{M}-\mathrm{H}]^{-}\right.$at $m / z$ 359) were positively identified as caffeic and rosmarinic acids according to their retention time, mass and UV-vis characteristics by comparison with the commercial standards. Compound 14, with

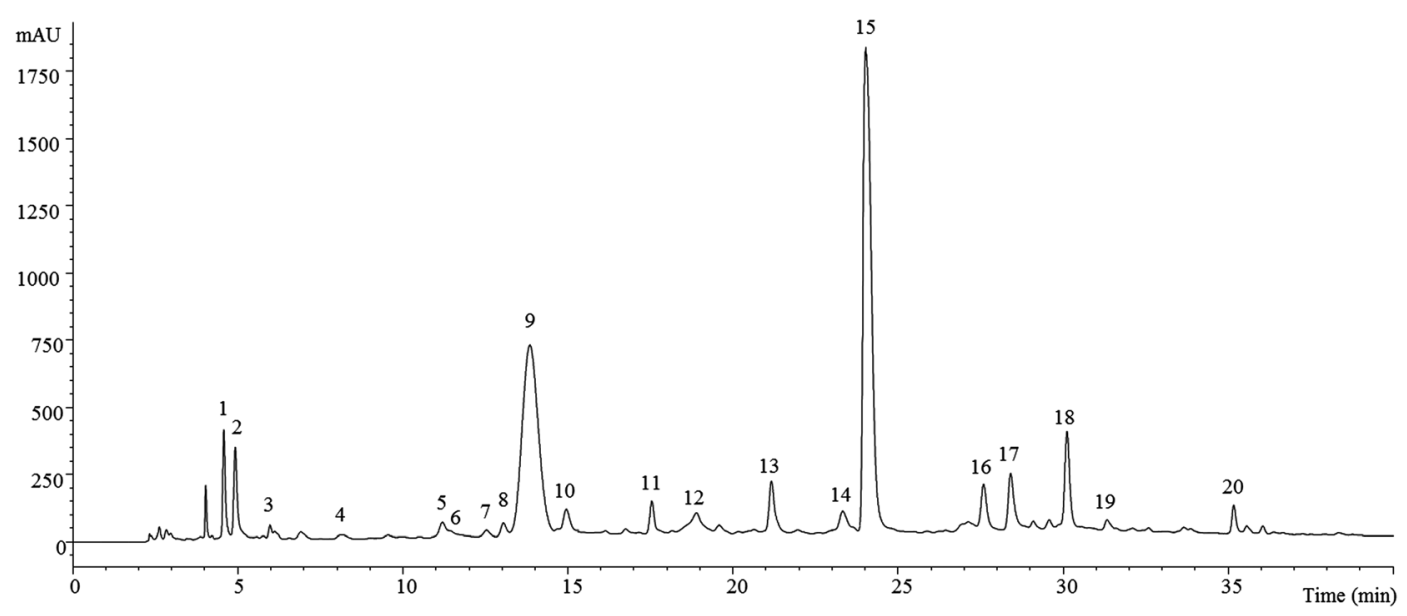

Fig. 1 Phenolic profile of $M$. officinalis decoction, recorded at $280 \mathrm{~nm}$. 
Table 1 Retention time $\left(R_{\mathrm{t}}\right)$, wavelengths of maximum absorption in the visible region $\left(\lambda_{\text {max }}\right)$, mass spectral data, tentative identification of phenolic compounds in $M$. officinalis decoctions

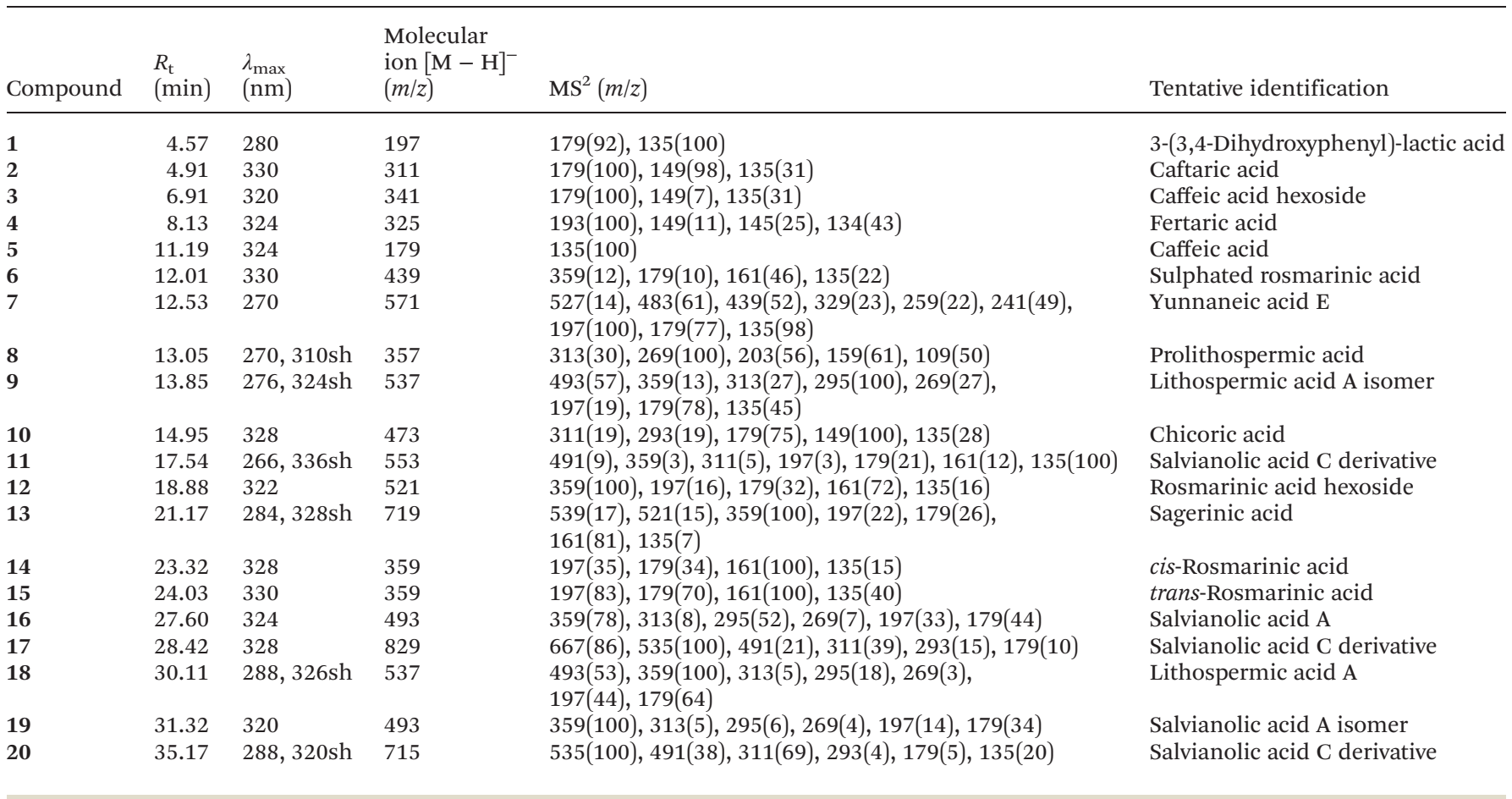

characteristics similar to compound $\mathbf{1 5}$, was tentatively identified as the cis isomer of rosmarinic acid. Hydroxycinnamoyl cis derivatives would be expected to elute before the corresponding trans ones, as observed after UV irradiation $(366 \mathrm{~nm}$, $24 \mathrm{~h})$ in our laboratory. Compounds $6\left([\mathrm{M}-\mathrm{H}]^{-}\right.$at $m / z$ 439) and $12\left([\mathrm{M}-\mathrm{H}]^{-}\right.$at $\left.m / z 521\right)$ yielded a fragment at $m / z 359$ (rosmarinic acid) from the loss of $80 \mathrm{mu}$ (sulphate moiety) and $162 \mathrm{mu}$ (hexoside moiety), respectively, which allowed their tentative identification as sulphated and hexoside derivatives of rosmarinic acid, as previously reported in M. officinalis infusions. ${ }^{3}$ Similarly, compound $3\left([\mathrm{M}-\mathrm{H}]^{-}\right.$at $\mathrm{m} / z$ 341) was assigned as a caffeic acid hexoside. Compounds $2\left([\mathrm{M}-\mathrm{H}]^{-}\right.$at $\mathrm{m} / \mathrm{z} 311), \mathbf{4}\left([\mathrm{M}-\mathrm{H}]^{-}\right.$at $\left.\mathrm{m} / \mathrm{z} 325\right)$ and $\mathbf{1 0}\left([\mathrm{M}-\mathrm{H}]^{-}\right.$at $\left.m / z 473\right)$ were tentatively identified as hydroxycinnamoyl tartaric esters, namely caftaric (caffeoyltartaric acid), fertaric (feruloyltartaric acid) and cichoric (dicaffeoyltartaric acid) acids, respectively, based on their mass spectra. ${ }^{20}$ Compound $8\left([\mathbf{M}-\mathbf{H}]^{-}\right.$at $\mathrm{m} / \mathrm{z}$ 357) presented a fragmentation pattern and the UV-vis spectra that allowed its identification as the caffeic acid dimer prolithospermic acid. ${ }^{19,20}$

Compounds 7, 9, 16, 18 and 19 were associated with caffeic acid trimers. Compound 7 presented a pseudomolecular ion $[\mathrm{M}-\mathrm{H}]^{-}$at $m / z 571$ releasing various fragments from the combination of successive losses of $44 \mathrm{mu}\left(\mathrm{CO}_{2}\right)$ and $197 \mathrm{mu}$ (dihydroxyphenyl-lactic acid). These characteristics are similar to the ones described for yunnaneic acid $\mathrm{E},{ }^{31}$ an identity that was tentatively associated with this compound. Compounds $\mathbf{9}$ and 18 showed the same pseudomolecular ion $\left([\mathrm{M}-\mathrm{H}]^{-}\right.$at $\mathrm{m} / \mathrm{z}$ 537), which may match the structure of salvianolic acids $\mathrm{H} / \mathrm{I}$ and lithospermic acid A. They were tentatively assigned as lithospermic acid A isomers due to the absence of a fragment $\mathrm{m} / \mathrm{z} 339$, as reported in the literature. ${ }^{17,20,22}$ Compound $\mathbf{1 8}$ was assigned as lithospermic acid A that was expected to elute later than rosmarinic acid..$^{17,18,20}$ Similar behaviour was observed in the infusions of M. officinalis. ${ }^{3}$ Compounds 16 and 19 presented a pseudomolecular ion $[\mathrm{M}-\mathrm{H}]^{-}$at $m / z$ 493, which together with their characteristic fragment ions at $\mathrm{m} / \mathrm{z} 313,295$ and $197^{20,22}$ and UV spectra allowed assigning them as salvianolic acid A isomers. Compound $\mathbf{1 6}$ was tentatively identified as salvianolic acid A that was expected to elute earlier than lithospermic acid A, as previously reported, ${ }^{3}$ whereas compound 19 was associated with a salvianolic acid $\mathrm{A}$ isomer.

Compound 13 showed a pseudomolecular ion $[\mathrm{M}-\mathrm{H}]^{-}$at $m / z 719$ releasing a main $\mathrm{MS}^{2}$ fragment at $m / z 359\left([\mathrm{M}-2 \mathrm{H}]^{2-}\right.$, rosmarinic acid) as well as other fragments characteristic of caffeic acid oligomers, which allowed its identification as sagerinic acid, a rosmarinic acid dimer that was also previously identified in $M$. officinalis infusions. ${ }^{3}$

No definite structure could be proposed for compounds $\mathbf{1 1}$ $\left([\mathrm{M}-\mathrm{H}]^{-}\right.$at $\left.m / z 553\right), 17\left([\mathrm{M}-\mathrm{H}]^{-}\right.$at $m / z$ 829) and 20 $\left([\mathrm{M}-\mathrm{H}]^{-}\right.$at $\left.m / z 715\right)$, although their fragmentation pattern allowed assignment of them as caffeic acid oligomers; furthermore, the presence of a common $\mathrm{MS}^{2}$ fragment at $\mathrm{m} / \mathrm{z} 491$ that may be attributed to salvianolic acid C, might suggest that they are derivatives of that compound. Compounds with similar characteristics as $\mathbf{1 7}$ and $\mathbf{2 0}$ were previously detected $^{3,30}$ in the samples of $M$. officinalis, although no structure was proposed, either. 
Table 2 Phenolic compound quantification in M. officinalis decoctions

\begin{tabular}{lc}
\hline Phenolic compound & $\begin{array}{c}\text { Content }\left(\mathrm{mg} \mathrm{g}^{-1}\right. \\
\text { lyophilized decoction })\end{array}$ \\
\hline 3-(3,4-Dihydroxyphenyl)-lactic acid & $6.5 \pm 0.2$ \\
Caftaric acid & $5.7 \pm 0.1$ \\
Caffeic acid hexoside & $1.1 \pm 0.1$ \\
Fertaric acid & $0.7 \pm 0.1$ \\
Caffeic acid & $2.2 \pm 0.1$ \\
Sulphated rosmarinic acid & $1.6 \pm 0.2$ \\
Yunnaneic acid E & $1.4 \pm 0.1$ \\
Prolithospermic acid & $2.2 \pm 0.1$ \\
Lithospermic acid A isomer & $62.5 \pm 0.3$ \\
Chicoric acid & $3.8 \pm 0.1$ \\
Salvianolic acid C derivative & $4.1 \pm 0.2$ \\
Rosmarinic acid hexoside & $4.9 \pm 0.4$ \\
Sagerinic acid & $7.9 \pm 0.3$ \\
cis-Rosmarinic acid & $5.1 \pm 0.2$ \\
trans-Rosmarinic acid & $83 \pm 1$ \\
Salvianolic acid A & $6.2 \pm 0.2$ \\
Salvianolic acid C derivative & $7.8 \pm 0.2$ \\
Lithospermic acid A & $10.9 \pm 0.3$ \\
Salvianolic acid A isomer & $2.1 \pm 0.1$ \\
Salvianolic acid C derivative & $2.84 \pm 0.02$ \\
Total phenolic compounds & $223 \pm 1$ \\
&
\end{tabular}

Quantification of the detected phenolic compounds expressed as rosmarinic or caffeic acid equivalents is shown in Table 2. Rosmarinic acid was the most abundant phenolic compound present in the decoctions; many authors have also reported this compound as the main phenolic compound in this species. ${ }^{3,24,26,28-30}$ Luteolin derivatives have also been reported as relevant phenolics in M. officinalis, ${ }^{3,23,25,28,30}$ but this type of derivatives (with low hydrophilicity) was absent in the decoction of $M$. officinalis. Rosmarinic acid has been reported as displaying high antioxidant and antibacterial activity. ${ }^{32}$

In terms of organic acids, the decoctions of $M$. officinalis presented oxalic, quinic, malic, shikimic, citric, succinic and fumaric acids. The higher quantities were found for quinic acid and the lower ones for fumaric acid as detailed in Table 3. When compared to decoctions of other plant species, namely Matricaria recutita L., quinic acid proved to be higher for M. officinalis ${ }^{33}$ furthermore, lemon balm decoctions contained higher contents in all organic acids when compared to Juglans regia L. leaves, although ascorbic acid was found in the latter species. ${ }^{34}$ Quinic acid is a normal constituent of our diet, capable of conversion to tryptophan and nicotinamide via the GI tract microflora, thus providing an in situ physiological source of these essential metabolic ingredients to humans. Pero, Lund, \& Leanderson ${ }^{35}$ conducted a clinical trial that confirmed the efficacy of quinic acid as an antioxidant, and extends its mode of action to include a basic nutritional benefit due to the enhanced metabolism of both tryptophan and nicotinamide, which are simultaneously induced by oral exposure to quinic acid.

The only free sugars detected in the decoctions of $M$. officinalis were fructose, glucose (the most abundant ones) and tre-
Table 3 Quantification of organic acids, free sugars and tocopherols in M. officinalis decoctions

\begin{tabular}{ll}
\hline Organic acids & Content $\left(\mathrm{mg} \mathrm{g}^{-1}\right.$ lyophilized decoction $)$ \\
Oxalic & $11.8 \pm 0.1$ \\
Quinic & $96.9 \pm 0.2$ \\
Malic & $18.8 \pm 0.1$ \\
Shikinic & $1.80 \pm 0.01$ \\
Citric & $24.1 \pm 0.1$ \\
Succinic & $26 \pm 1$ \\
Fumaric & $0.032 \pm 0.001$ \\
Total & $179 \pm 1$ \\
& \\
Sugars & Content $\left(\mathrm{mg} \mathrm{g}^{-1}\right.$ lyophilized decoction $)$ \\
Fructose & $49 \pm 4$ \\
Glucose & $47 \pm 1$ \\
Trehalose & $19.8 \pm 0.2$ \\
Total & $116 \pm 5$ \\
& \\
Tocopherols & Content $\left(\mu \mathrm{g} \mathrm{g}^{-1}\right.$ lyophilized decoction $)$ \\
$\alpha$-Tocopherol & $0.44 \pm 0.02$ \\
$\gamma$-Tocopherol & $1.43 \pm 0.05$ \\
Total & $1.87 \pm 0.03$
\end{tabular}

halose as depicted in Table 3. When compared to other decocted samples like wild Tuberaria lignosa (Sweet) Samp. ${ }^{10}$, J. regia ${ }^{34}$ and Castanea sativa Mill. ${ }^{7}$, M. officinalis proved to have a much lower content of sugars.

Tocopherols, which are isoforms of vitamin E, the most important lipophilic vitamin for the human metabolism, were also found in the decoctions (Table 3). Only $\alpha$ - and $\gamma$-isoforms were found, with the latter being the most abundant one. As expected, the quantity of $\gamma$-tocopherol found in these decoctions was lower than the one reported in a previous study with garden cultivated, in vitro cultured, commercial bag and granulated M. officinalis plants (results expressed in dry weight and after extraction with non-polar solvents); this is certainly related with the lower extractability of these compounds using water. $^{36}$

\subsection{Bioactive properties}

Regarding the decoctions' antibacterial activity (Table 4), the most sensitive bacteria were Pseudomonas aeruginosa and Salmonella typhimurium, and for the last case even better than the positive controls. The decoctions gave the same MBC as ampicillin against Staphylococcus aureus, and the same MIC as streptomycin against $P$. aeruginosa. In terms of antifungal activity, M. officinalis decoctions displayed higher activity, with Penicillium funiculosum being more sensitive to the decoction than the two positive controls (bifonazole and ketoconazole). The behaviour of the decoctions against Aspergillus versicolor, A. ochraceus, Trichoderma viride and P. ochrochloron was better than the positive control ketoconazole (lower MICs and MFCs).

The antioxidant activity of the decoctions was determined by DPPH scavenging activity, reducing power, $\beta$-carotene bleaching inhibition and neutralization of thiobarbituric reactive species. The DPPH scavenging activity and reducing power of the decoctions were higher than their lipid peroxidation 
Table 4 Minimum inhibitory (MIC) and bactericidal (MBC) or fungicidal (MFC) concentrations of $M$. officinalis lyophilized decoctions, expressed in $\mathrm{mg} \mathrm{mL}^{-1}$

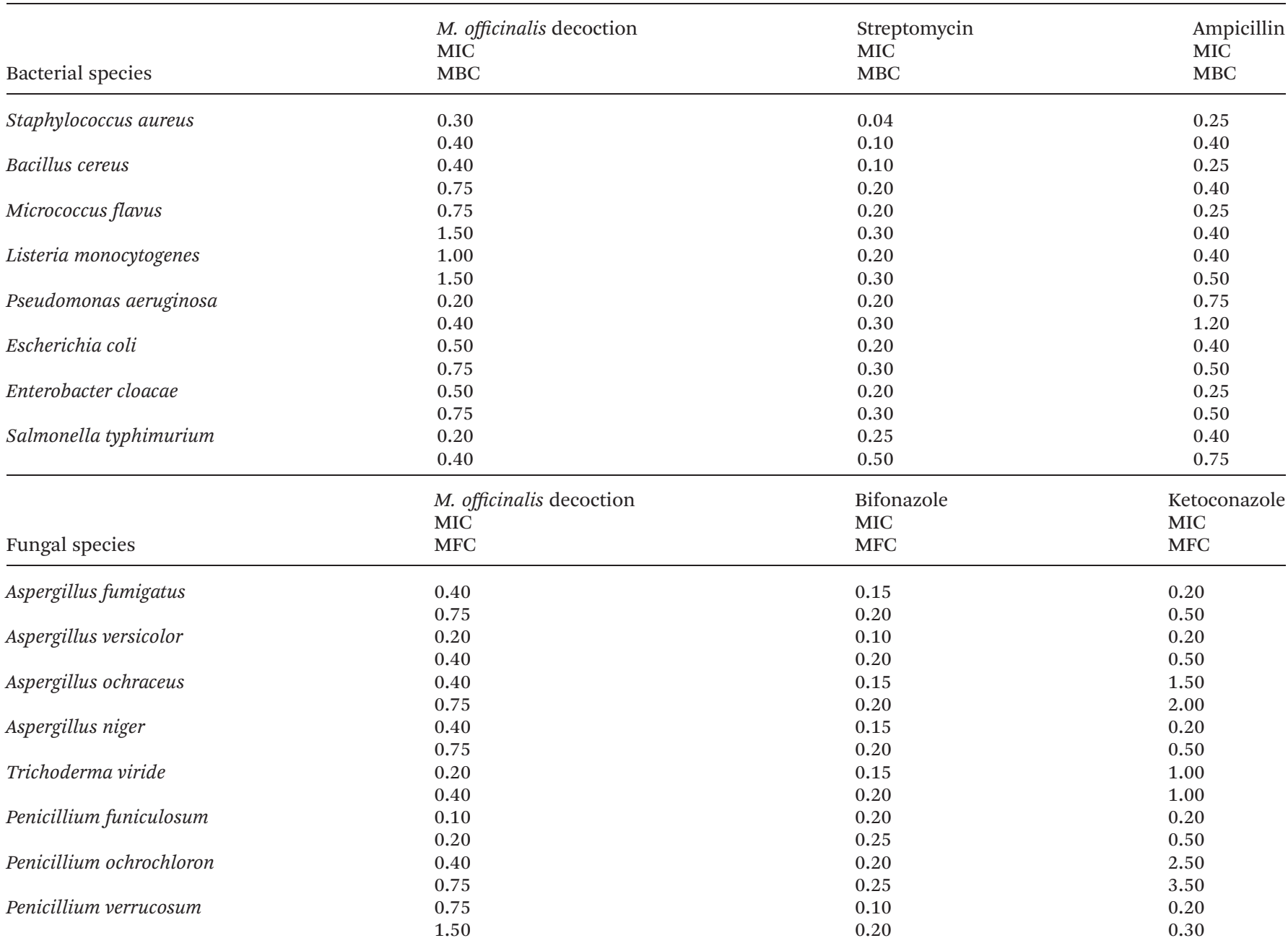

inhibition capacity (Table 5). These differences could be explained by the different underlying mechanisms involved in each type of the antioxidant reaction and the interaction between radical and antioxidant species. ${ }^{37}$ To obtain a better overview of the antioxidant power of the studied decoctions, for the DPPH and reducing power assays, they yielded higher activity (lower $\mathrm{EC}_{50}$ values) than the methanolic extracts of M. officinalis ${ }^{36}$ and Chenopodium ambrosioides L., ${ }^{9}$ infusions of Cynara scolymus L., C. ambrosioides, ${ }^{9}$ Silybum marianum (L.) Gaertn, and Cochlospermum angolensis Welw., ${ }^{38}$ decoctions of Chamaemelum nobile L., ${ }^{11} \mathrm{~J}$. regia, ${ }^{34}$ M. recutita, ${ }^{33}$ Ginkgo biloba L., ${ }^{39}$ Origanum vulgare L., ${ }^{2}$ C. sativa flowers ${ }^{7}$ and Taraxacum sect. Ruderalia. ${ }^{40}$

The antitumor activity was evaluated against human tumor cell lines, namely against breast (MCF-7), non-small lung (NCI-H460), cervical (HeLa) and hepatocellular carcinoma (HepG2) (Table 5). The best inhibition was detected for the MCF-7 cell line and the least affected cell line was the NCI-H460. Although not outstandingly low when compared to the positive control (ellipticine), the decoctions did not show any hepatotoxicity (tested against the porcine liver cell primary culture PLP2), while ellipticine had very strong toxic effects. By comparing their antitumor activity to other decocted and infused plant samples, $M$. officinalis proved to be better against the HepG2 cell line than hepatoprotective plants such as $S$. marianum and C. angolensis, ${ }^{38}$ C. nobile, ${ }^{11}$ C. ambrosioides, ${ }^{9} \mathrm{~J}$. regia ${ }^{34}$ and $M$. recutita. ${ }^{33}$ Furthermore, the four latter species had higher $\mathrm{GI}_{50}$ for all the assayed cell lines, when compared to M. officinalis.

\section{Conclusions}

M. officinalis decoctions proved to be a very good source of rosmarinic acid and lithospermic acid A, quinic acid and $\gamma$-tocopherol. Rosmarinic acid might be one of the compounds responsible for the various bioactive properties attributed to lemon balm including the antibacterial and antioxidant 
Table 5 Antioxidant, antitumor and hepatotoxic activities of M. officinalis lyophilized decoctions ${ }^{a}$

\begin{tabular}{|c|c|}
\hline Antioxidant activity & $\mathrm{EC}_{50}$ values $\left(\mu \mathrm{g} \mathrm{mL}^{-1}\right)$ \\
\hline DPPH scavenging activity & $49 \pm 5$ \\
\hline Reducing power & $35 \pm 1$ \\
\hline$\beta$-Carotene bleaching inhibition & $6073 \pm 348$ \\
\hline TBARS inhibition & $271 \pm 2$ \\
\hline Antitumor activity & $\mathrm{GI}_{50}$ values $\left(\mu \mathrm{g} \mathrm{mL}^{-1}\right)$ \\
\hline MCF-7 (breast carcinoma) & $51 \pm 4$ \\
\hline NCI-H460 (non-small cell lung carcinoma) & $258 \pm 17$ \\
\hline HeLa (cervical carcinoma) & $155 \pm 10$ \\
\hline HepG2 (hepatocellular carcinoma) & $67 \pm 2$ \\
\hline Hepatotoxicity & $\mathrm{GI}_{50}$ values $\left(\mu \mathrm{g} \mathrm{mL}^{-1}\right)$ \\
\hline PLP2 & $>400$ \\
\hline \multicolumn{2}{|c|}{ 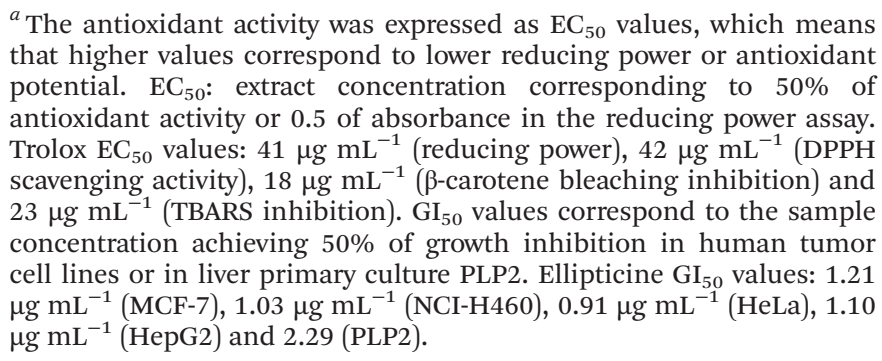 } \\
\hline
\end{tabular}

effects. The antimicrobial activity of the decoctions was observed against a variety of bacteria and fungi, supporting the claims as an antiseptic, especially against $P$. aeruginosa, $S$. typhimurium and P. funiculosum. The antioxidant activity was also outstanding, due to the very low $\mathrm{EC}_{50}$ values obtained for DPPH scavenging activity and reducing power, placing the decoctions of this medicinal plant as one of the most powerful antioxidants assayed, supporting their consumption as a functional beverage against oxidative stress. Finally, the activity against specific tumor cell lines proved to be quite satisfactory, yielding lower $\mathrm{GI}_{50}$ values, especially against HepG2 cell lines, when compared to some hepatoprotective plants. No hepatotoxicity was observed for the studied decoctions, which favours their consumption as functional beverages, given their pleasant taste.

\section{Conflict of interest}

The authors state no conflict of interest regarding this manuscript.

\section{Acknowledgements}

The authors are grateful to the company Mais Ervas, Lda. for providing the M. officinalis samples. The authors also acknowledge the PRODER project no. 46577-Plant Lact., the Foundation for Science and Technology (FTC, Portugal) for financial support to CIMO (Pest-OE/AGR/UI0690/2011) and L. Barros, and the Serbian Ministry of Education, Science and Technological Development for the Grant No. 173032 .

\section{References}

1 A. Crozier, M. N. Clifford and H. Ashihara, Plant secondary metabolites. Occurrence, structure and the role in human diet, Blackwell Publishing, Oxford, 2006.

2 E. N. Martins, N. T. C. Pessano, L. Leal, D. H. Roos, V. Folmer, G. C. Puntel, J. B. T. Rocha, M. Aschner, D. S. Ávila and R. L. Puntel, Brain Res. Bull., 2012, 87, 74-79.

3 L. Barros, M. Dueñas, M. I. Dias, M. J. Sousa, C. SantosBuelga and I. C. F. R. Ferreira, Food Chem., 2013, 136, 1-8.

4 R. P. Pereira, A. A. Boligon, A. S. Appel, R. Fachinetto, C. S. Ceron, J. E. Tanus-Santos, M. L. Athayde and J. B. T. Rocha, Ind. Crops Prod., 2014, 53, 34-45.

5 I. Berasategi, I. Navarro-Blasco, M. I. Calvo, R. Y. Cavero, I. Astiasarán and D. Ansorena, Meat Sci., 2014, 96, 11851190.

6 L. R. Juneja, M. P. Kapoor, T. Okubo and T. P. Rao, Green tea polyphenols: Nutraceuticals of modern life, Taylor \& Francis, CRC Press, Boca Raton, 2013.

7 M. Carocho, L. Barros, A. Bento, C. Santos-Buelga, P. Morales and I. C. F. R. Ferreira, Biomed. Res. Int., 2014, 232956.

8 M. Carocho, R. C. Calhelha, M. J. R. P. Queiroz, A. Bento, P. Morales, M. Soković and I. C. F. R. Ferreira, Ind. Crops Prod., 2014, 62, 42-46.

9 L. Barros, E. Pereira, R. C. Calhelha, M. Dueñas, A. M. Carvalho, C. Santos-Buelga and I. C. F. R. Ferreira, J. Funct. Foods, 2013, 5, 1732-1740.

10 J. Pinela, L. Barros, M. Dueñas, A. M. Carvalho, C. SantosBuelga and I. C. F. R. Ferreira, Food Chem., 2012, 135, 1028-1035.

11 R. Guimarães, L. Barros, M. Dueñas, R. C. Calhelha, A. M. Carvalho, C. Santos-Buelga, M. J. R. P. Queiroz and I. C. F. R. Ferreira, Food Chem., 2013, 136, 718-725.

12 J. Petrović, D. Stojković, F. S. Reis, L. Barros, J. Glamočlija, A. Ćirić, I. C. F. R. Ferreira and M. Soković, Food Funct., 2014, 5, 1441-1451.

13 V. Vieira, A. Fernandes, L. Barros, J. Glamočlija, A. Ćirić, D. Stojković, A. Martins, M. Soković and I. C. F. R. Ferreira, J. Sci. Food Agric., 2015, DOI: 10.1002/jsfa.7063.

14 A. Espinel-Ingroff, J. Clin. Microbiol., 2001, 39, 1360-1367.

15 M. J. Alves, I. C. F. R. Ferreira, I. Lourenço, E. Costa, A. Martins and M. Pintado, Pathogens, 2014, 3, 667-679.

16 Y. Lu and L. Y. Foo, Phytochemistry, 2002, 59, 117-140.

17 G. Zeng, H. Xiao, J. Liu and X. Liang, Rapid Commun. Mass Spectrom., 2006, 20, 499-506.

18 Z. Zhu, H. Zhang, L. Zhao, X. Dong, X. Li, Y. Chai and G. Zhang, Rapid Commun. Mass Spectrom., 2007, 21, 18551865. 
19 L. N. Zhou, X. Zhang, W. Z. Xu, X. N. Ma, Z. Jia, Y. M. Zheng and S. Yo, Phytochem. Anal., 2001, 22, 378384.

20 H. Chen, Q. Zhang, X. Wang, J. Yang and Q. Qang, Phytochem. Anal., 2011, 22, 247-257.

21 N. Nuengchamnong, K. Krittasilp and K. Ingkaninan, Food Chem., 2011, 59, 139-143.

22 M. Ruan, Y. Li, X. Li, J. Luo and L. Kong, J. Pharm. Biomed. Anal., 2012, 59, 184-189.

23 A. Heitz, A. Carnat, D. Fraisse, A. P. Carnat and J. L. Lamaison, Fitoterapia, 2000, 71, 201-202.

24 A. Caniova and C. Brandsteterova, J. Liq. Chromatogr. Relat. Technol., 2001, 24, 2647-2659.

25 J. Patora and B. Klimek, Pol. Pharm. Soc., 2002, 59, 139143.

26 A. Ziaková and E. Bransteterová, J. Liq. Chromatogr. Relat. Technol., 2003, 26, 443-453.

27 C. Proestos, N. Chorianopoulos, G. J. E. Nychas and M. Komaitis, J. Agric. Food Chem., 2005, 53, 11901195.

28 I. Fecka and S. Turek, J. Agric. Food Chem., 2007, 55, 1090810917.

29 J. Lee, J. Funct. Foods, 2010, 2, 158-162.

30 T. L. Miron, M. Herrero and E. Ibáñez, J. Chromatogr. A, 2013, 127, 1287-1293.
31 D. Guo, J. Zhang, M. Zhu, X. Fan, Y. Wu, A. Liu, M. Yang and $\mathrm{H}$. Qu, Fingerprinting study in Medicine, volume 2, Pharmacology and Quality Control, Springer Dordrecht Heidelberg, New York, London, 2008.

32 M. Petersen and M. S. J. Simmonds, Phytochemistry, 2003, 62, 121-125.

33 R. Guimarães, L. Barros, M. Dueñas, R. C. Calhelha, A. M. Carvalho, C. Santos-Buelga, M. J. R. P. Queiroz and I. C. F. R. Ferreira, Food Chem., 2013, 136, 947-954.

34 A. Santos, L. Barros, R. C. Calhelha, M. Dueñas, A. M. Carvalho, C. Santos-Buelga and I. C. F. R. Ferreira, Ind. Crops Prod., 2013, 51, 430-436.

35 R. W. Pero, H. Lund and T. Leanderson, Phytother. Res., 2009, 23, 335-346.

36 M. I. Dias, L. Barros, M. J. Sousa and I. C. F. R. Ferreira, Food Chem. Toxicol., 2012, 50, 1866-1873.

37 M. Carocho and I. C. F. R. Ferreira, Food Chem. Toxicol., 2013, 51, 15-25.

38 C. Pereira, R. C. Calhelha, L. Barros and I. C. F. R. Ferreira, Ind. Crops Prod., 2013, 49, 61-65.

39 E. Pereira, L. Barros and I. C. F. R. Ferreira, Ind. Crops Prod., 2013, 51, 244-248.

40 M. I. Dias, L. Barros, R. C. Alves, M. B. P. P. Oliveira, C. Santos-Buelga and I. C. F. R. Ferreira, Food Res. Int., 2014, 156, 266-271. 